\title{
Post-traumatic growth after cancer: a scoping review of qualitative research
}

\author{
Fiona Menger ${ }^{1}\left[\right.$ D Nurul Asyiqin Mohammed Halim² ${ }^{2}$ Ben Rimmer $^{3} \cdot$ Linda Sharp $^{3}$
}

Received: 26 February 2021 / Accepted: 26 April 2021 / Published online: 20 May 2021

(c) The Author(s) 2021

\begin{abstract}
Purpose Interest is growing in post-traumatic growth (PTG) after cancer prompted, in part, by observations of positive associations with health-related quality of life. Qualitative research provides valuable insight into survivors' experiences. We conducted a scoping review of qualitative evidence on PTG in cancer, determining the number, nature, range and scope of studies, and gaps in the literature.

Methods We systematically searched Medline, Scopus, CINAHL, Web of Science, and PsycINFO for qualitative research exploring positive changes after cancer published from 1996. From eligible studies, we extracted: terms used for PTG; design, methodological orientation, and techniques, and participant characteristics. Using descriptive mapping, we explored whether study findings fit within Tedeschi and Calhoun's PTG framework, and evidence for unique positive changes post-cancer.

Results Twenty-eight studies were eligible. Cancer sites included were: breast, 14; mixed, 6; haematological, 4; head and neck cancer, 2; bone, 1, and testis, 1. Multiple studies were conducted in: the USA (12), Australia (3), Iran (2), and the UK (2). Twenty-three studies collected data using individual interviews (21) or focus groups (2). Definitions of PTG varied. Studies largely focused on descriptive accounts of PTG. Findings mapped onto existing PTG dimensions; health behaviour changes were often reported, under 'new possibilities'.

Conclusions A range of PTG outcomes can occur after cancer. Positive health behaviour changes warrant further exploration. Future research should include more diverse patient populations, collect longitudinal data, and focus on pathways towards positive changes.
\end{abstract}

Keywords Post-traumatic growth $\cdot$ Cancer $\cdot$ Survivorship $\cdot$ Coping

\section{Introduction}

The increasing number of cancer survivors worldwide $[1,2]$ has led to greater focus over the past 10-20 years on investigating and understanding survivors' needs, experiences, and outcomes. Most of that research has focused on identifying problems, limitations, and adverse impacts of cancer on people's lives [3], with the goal of developing services, supports, and interventions to ameliorate these impacts.

Fiona Menger

fiona.menger@ncl.ac.uk

1 School of Education, Communication and Language Sciences, Newcastle University, Newcastle upon Tyne, UK

2 Newcastle University Medicine Malaysia, Johor, Malaysia

3 Population Health Sciences Institute, Newcastle University Centre for Cancer, Newcastle University, Newcastle upon Tyne, UK
However, interest has also grown in exploring the potential for survivors to experience positive consequences of their illness. For example, survivors can report positive behavioural, emotional, or cognitive changes following cancer, such as an enhanced sense of appreciation of life, more meaningful relationships, or a richer existential and spiritual life [4-6].

These changes are commonly referred to as post-traumatic growth (PTG). The term was first described by Tedeschi and Calhoun in relation to responses to wider experiences of trauma, e.g., survivorship of a natural disaster [7]. These authors argue that traumatic events (such as cancer and its treatment) are, in themselves, insufficient to cause PTG. Instead, an individual must reflect on their experiences and seek to find meaning in them, i.e., growth arises from adaptation to the trauma and rebuilding one's sense of the world [8].

Quantitative data suggests that a substantial proportion of cancer survivors experience PTG [9-11]. Moderate-high 
growth has been reported in around $60 \%$ of survivors [12, 13]. In terms of correlates, age, sex, time since diagnosis, type of treatment, and cancer stage have been associated with PTG, but evidence is inconsistent $[9,10]$. More consistent positive relationships with social support and resilience have been reported $[9,14]$ and PTG is positively associated with health-related quality of life [15]. However, while this body of research has been valuable in quantifying the extent of PTG among survivors, it has limitations, including crosssectional designs and significant heterogeneity $[15,16]$. Nor can it shed light on pathways by which PTG develops or whether any aspects of the experience of PTG are specific to cancer.

Qualitative research methods seek to understand people's experiences, providing detailed, rich, and deep data. By exploring how a phenomenon manifests and is experienced and by whom, the context in which it occurs, and what may influence or affect that experience, qualitative data - and reviews of the body of qualitative data - can help identify gaps in knowledge and understanding [17]. Further, it can form an essential underpinning in the rigorous development of interventions $[18,19]$.

We undertook a scoping review to address the following research questions:

(1) What is the extent, range, and nature of existing qualitative research on PTG in survivors of cancer?

(2) Do findings from existing qualitative research on PTG after cancer fit with wider descriptions of PTG or are there unique positive changes after cancer?

\section{Methods}

Where there is lack of clarity on the extent of literature on a topic or on the types of evidence available, a scoping review is appropriate [20]. To address our first research question, we were guided by Arksey and O'Malley's stages of a scoping review: identifying relevant studies, study selection, charting the data, and collating, summarising, and reporting the results [21]. (We had already defined our research questions, so the first stage of Arseky \& O'Malley was not relevant.) To address our second research question, which leaned more towards qualitative evidence synthesis, we followed the initial stages of a pragmatic descriptive mapping approach [22]. For review conduct and reporting, we were guided by Preferred Reporting Items for Systematic Reviews and Meta-Analyses extension for Scoping Reviews (PRISMA-ScR) [23].

\section{Identifying relevant studies}

We searched Medline, Scopus, CINAHL, Web of Science, and PsycINFO from 1996 onwards, as this year marked the first paper published by Tedeschi and Calhoun using the term post-traumatic growth [24]. A combination of MeSH headings and text words were used, representing the phenomenon of interest (PTG), the trauma of interest (cancer), and the study methodology (qualitative). The search was executed on 5 July 2019, with database alerts used to identify any further studies by 10 April 2020. Online Resource 1 provides a table illustrating an example search strategy.

\section{Study selection}

After initially scanning the search results, we defined our inclusion criteria as follows:

- Primary qualitative research based on original data, or mixed methods studies which reported qualitative data separately, reported in full and published in English;

- Studies which aimed to identify or explain PTG; recognising not all have used the same terminology, we also included those that did not use this term but used terms that could be used synonymously (e.g., stress-related growth and adversarial growth);

- Studies including participants with any type of cancer diagnosed in adulthood. Survivors of childhood cancer are likely to experience unique issues and challenges due to their life stage and thus their experiences of PTG may be different;

- Studies conducted with individuals who had sufficient time following treatment for rumination and reflection to occur and for PTG to develop. Guided by Tedeschi and Calhoun's definition of PTG [25], participants had to be at least 6 months post-diagnosis of cancer or 3 months after completion of treatment;

- Studies which recruited cancer survivors and others, but where data could be separately extracted from survivor participants.

Unpublished doctoral dissertations were included, unless a peer reviewed paper reporting the results had also been identified. We excluded studies which comprised participants described as being at the end of life or undergoing palliative care, as their experiences of PTG may be quite specific. We also excluded studies which focused on general experiences of cancer survivorship (rather than PTG) and those which examined PTG solely from the perspective of those other than the cancer survivor (e.g., spouses and informal carers). Finally, we excluded studies which set out to consider only one aspect of positive change.

Following deduplication of search results, titles and abstracts were screened in Rayyan [26], independently by two authors (FM, NMH). Any conflicts were discussed. Full text review of potentially eligible studies 
was conducted by the same two authors. Any conflicts were resolved by discussion or consultation with a third author (LS). Reference lists of eligible studies were hand checked for any additional studies which had been missed.

\section{Data charting, summary, and synthesis}

To address our first research question, we charted data on study aims and characteristics (including where conducted, cancer sites, and participants' characteristics). Terms used to describe PTG or the construct considered in the paper, and any definitions provided, were documented. This was initially conducted by one author (NMH) and then checked by a second author (BR). Following initial charting, we tabulated characteristics of all included studies to summarise the extent, range, and nature of existing qualitative research on PTG after cancer.

We then examined each charted definition to determine whether the authors' discussion of the construct being examined contained reference to positive changes: (1) following a life struggle or traumatic event; (2) being unplanned or unexpected; (3) occurring a period of time after the trauma or following a period of rumination or reflection, and (4) being a process as well as outcome [25].

We charted information on methodological stance and data collection and analysis methods using Bradbury et al.'s Qualitative Research Level of Alignment Wheel (QR_LAW ${ }^{\mathrm{TM}}$ ) [27]. This enabled comparison of the philosophical orientation of the work and the qualitative methods/techniques used to investigate PTG. We also collated (where reported) example questions that reflected how data was elicited from study participants.

To address our second research question, findings from eligible studies (textual descriptions from the results section or elsewhere in the paper and quotes) were collated and mapped to Tedeschi and Calhoun's PTG outcomes: relating to others, new possibilities, personal strength, spiritual change, and appreciation of life. Any findings which did not fit within one of these categories were collated separately. This was done by one author (NMH) and checked by two others (FM, BR) with discussion, as required, to reach consensus. For mixed methods studies, only qualitative findings were abstracted.

\section{Results}

\section{Search results}

The searches resulted in 1657 citations with an additional two studies identified through database alerts. Following deduplication, titles and abstracts of 1184 records were screened. Full texts of 46 studies were reviewed and, of these, 28 studies were eligible for inclusion (Fig. 1).

\section{Study aims}

Of the 28 studies [28-55], five aimed to explore both positive and negative experiences $[28,32,41,49,54]$ and 15 were focused only on positive experiences, either framed in terms of PTG or positive constructs such as meaning-making [30, 33-38, 43, 45-48, 51, 53, 55]. In six studies, the stated aim was broader (e.g., the original research question had a focus on areas such as adjustment or lasting life changes after cancer) but results were reported with a focus on the positive changes found $[29,31,39,42,44,52]$. Two studies had very specific aims - exploring differences between people with cancer and their spouses in terms of growth [40] and an examination of growth in relation to other constructs, such as lifestyle changes [50].

\section{Study characteristics}

Table 1 summarises characteristics across all studies. Tables 2 and 3 show, for each study, characteristics of participants and aims, orientations, and techniques, respectively.

\section{Terms used to describe post-traumatic growth}

Eighteen studies used the term post-traumatic growth; the remaining studies used a diverse range of terms (Online Resource Table 2). All definitions mentioned positive change, but the nature of any change was inconsistently defined; terms used included 'psychological', 'meaningful', or 'mental' change, 'emotional growth', and 'changed sense of self'. Only one study (which used the term PTG [45]) mentioned the need for time to pass for PTG to develop. Three studies [35, 38, 45] overtly mentioned a 'process' or 'journey' of change within their definitions.

\section{Study samples}

Studies on breast cancer - and therefore, women - dominated $(n=14)$ (Table 1$)$. Of the remaining studies, six included survivors of mixed cancer sites, four included survivors of haematological cancer, two were with head and neck cancer survivors, while there was one study of bone cancer and one of testicular cancer. Twelve studies were conducted in the USA, three in Australia, and two each in Iran and the UK; the remaining nine were each from a different country. Due to differences in study design and data collection methods, sample sizes ranged from six to $5149 ; 20$ studies included $\leq 50$ participants and 11 

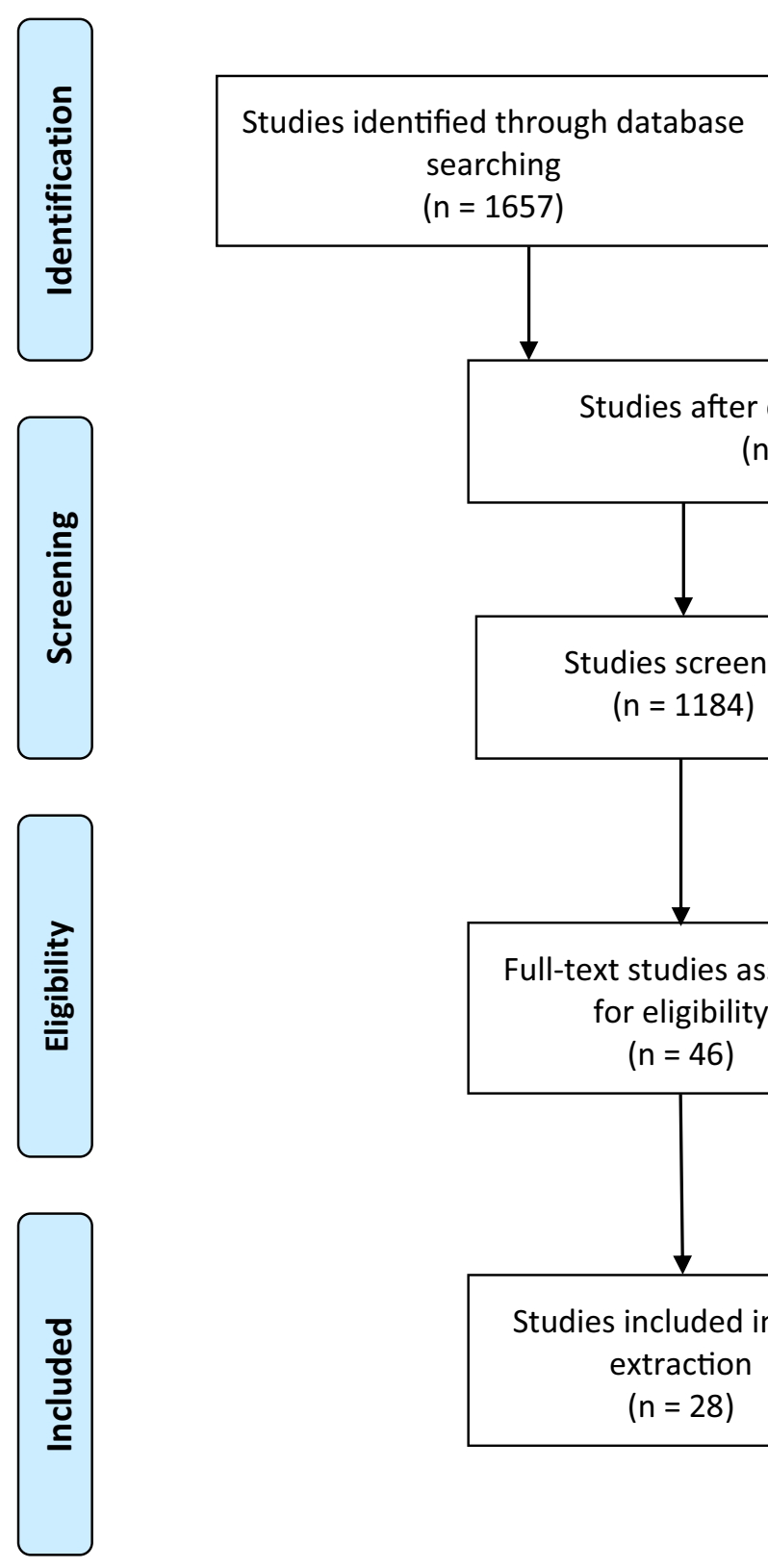

$(\mathrm{n}=1657)$

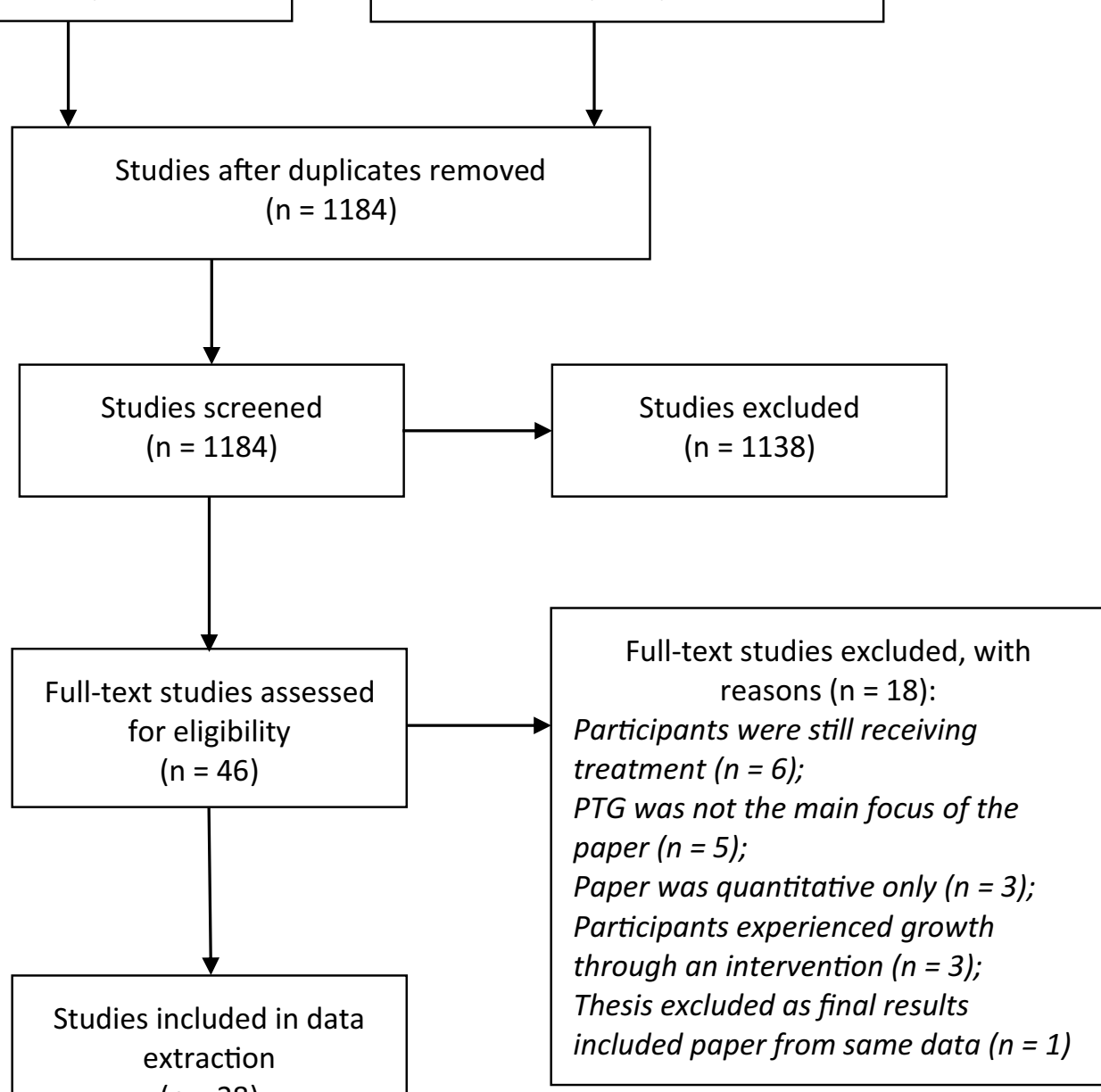

Fig. 1 PRISMA flow diagram of eligible studies

included $\leq 15$. Studies varied in the time that had elapsed between cancer diagnosis or treatment and data collection. Within individual studies, between participant differences were common: for example, Cheng et al. [54] reported that time since diagnosis was anywhere between 6 months and 15 years. All studies were cross-sectional, collecting data at one point in time.

\section{Study orientation and techniques}

Sixteen studies were purely qualitative, while the other 12 used mixed methods. Fourteen purely qualitative studies conducted individual interviews, mostly described as semistructured. One study carried out group interviews [51], while one described collecting open-ended written responses [37]. Of the mixed methods studies, seven conducted interviews as a separate qualitative component, while the other five used an open-ended questionnaire (two studies) or an open-ended item at the end of the quantitative component (e.g., text box at end of survey; three studies).

Thirteen studies did not report a methodological standpoint or philosophical position; these were labelled as taking a generic qualitative approach. Where a philosophical approach was named, the most common standpoint was 
Table 1 Summary of included study characteristics $(n=28)$

\begin{tabular}{llll}
\hline Study characteristics & $n(\%)$ & Study characteristics & $n(\%)$ \\
\hline Country & & Sample size & \\
USA & $12(42.9)$ & $\leq 15$ & $11(39.2)$ \\
Australia & $3(10.7)$ & $16-50$ & $9(32.2)$ \\
Iran & $2(7.1)$ & $>51$ & $8(28.6)$ \\
UK & $2(7.1)$ & Study design \\
Other ${ }^{1}$ (1 paper each) & $9(32.2)$ & Qualitative & $16(57.1)$ \\
Cancer site & & Mixed methods & $12(42.9)$ \\
Breast & $14(50)$ & Orientation (methodological or & \\
& & philosophical position) & \\
Mixed & $6(21.4)$ & Generic qualitative & $13(46.4)$ \\
Haematological & $4(14.3)$ & Phenomenology & $9(32.2)$ \\
Head and neck & $2(7.1)$ & Grounded theory & $3(10.7)$ \\
Bone & $1(3.6)$ & Narrative & $2(7.1)$ \\
Testicular & $1(3.6)$ & Case study & $1(3.6)$ \\
Findings in relation to PTG outcomes & \\
Relating to others & & Data generation technique ${ }^{b, c}$ & \\
New opportunities & $26(92.9)$ & Individual interviews & $21(72.4)$ \\
Personal strength & $23(82.1)$ & Other techniques & $5(17.2)$ \\
Spiritual change & $27(96.4)$ & Focus groups & $2(6.9)$ \\
Appreciation of life & $19(67.9)$ & Narrative interview & $1(3.5)$ \\
Number of PTG outcomes reported & $25(89.3)$ & Data analysis technique & \\
Five & & Thematic analysis & $9(32.2)$ \\
Four & $16(57.1)$ & Content analysis & $5(17.9)$ \\
Three & $6(21.4)$ & Phenomenological analysis & $4(14.3)$ \\
Two & $4(14.3)$ & Constant comparison & $4(14.3)$ \\
\hline & $2(7.1)$ & Other & $6(21.3)$ \\
\hline
\end{tabular}

${ }^{a}$ Other countries: China, France, India, Italy, Japan, North America, Norway, Switzerland, and Turkey

${ }^{\mathrm{b}}$ One study conducted both interviews and focus groups [46] and has been counted twice

${ }^{\mathrm{c}}$ Data generation and analysis techniques were mapped to the QR_LAW[25] phenomenology (nine) or grounded theory (three). Two studies took a narrative approach, and one a case study approach.

Sixteen studies (six purely qualitative; ten mixed methods) provided one or more examples of questions used to elicit qualitative data (Table 3). Seven studies reported asking quite broad questions relating to how life had changed following cancer [38, 41, 45-47, 49, 54]; six stated that they explicitly asked participants to discuss any positive changes they had experienced [35, 40, 43, 44, 48, 50]; example questions from remaining studies tended to refer to more specific changes, e.g., relationships with others $[28,54]$ or personal strength [29].

The most described analysis techniques were thematic analysis (nine studies), phenomenological analysis (four), content analysis (five), or constant comparison (four). Other approaches included framework (two), narrative analysis (one), and discourse/text analysis (one). Two studies, classified in Table 3 as 'other', used techniques described as redemptive sequence analysis of narrative markers [55] and a published coding process technique [34].

\section{Findings in relation to PTG outcomes}

Online Resource Table 3 maps study findings to Tedeschi and Calhoun's five PTG outcomes. Sixteen studies had findings within all five PTG outcomes; six studies mapped on to four outcomes; four studies mapped on to three outcomes, and two studies mapped onto two outcomes. There were no findings which did not map onto one of these outcomes.

\section{Relating to others}

Twenty-six studies reported findings relevant to the 'Relating to others' outcome. Survivors described how their experience had helped them prioritise, and improve, important relationships: 'It is one of the best things that has ever happened to me; it made family relationships better' [41, p6]. Survivors acknowledged that relationships with others are likely to change over the course of their cancer journey, and this helped them recognise who is important and who they should value. 
Table 2 Characteristics of study participants

\begin{tabular}{|c|c|c|c|c|c|c|}
\hline Source (country) & Sample size & Cancer site & $\operatorname{Age}^{\mathrm{a}}$ & Sex & Time since diagnosis ${ }^{b}$ & Time since treatment ${ }^{\mathrm{b}}$ \\
\hline Fromm et al. [28] (USA) & 90 & Haematological & 38.8 & $\mathrm{M}(58 \%), \mathrm{F}(42 \%)$ & 28.9 months & 49.5 months \\
\hline Carpenter et al. [29] (USA) & 60 & Breast & 53.7 & $\mathrm{~F}(100 \%)$ & 30.8 months & 27.1 months \\
\hline McGrath [38] (Australia) & 12 & Haematological & $25-60$ & $\mathrm{M}(66.7 \%), \mathrm{F}(33.3 \%)$ & $3-15$ years & $1-10$ years \\
\hline Dahan et al. [39] (USA) & 6 & Haematological & $50-66$ & $\mathrm{M}(50 \%), \mathrm{F}(50 \%)$ & NR & $>3$ months \\
\hline Ruf et al. [40] (Switzerland) & 31 & Head and neck & 58.2 & $\mathrm{M}(100 \%)$ & 3.7 years & $>6$ months \\
\hline Hegelson [41] (USA) & 180 & Breast & 59.43 & $\mathrm{~F}(100 \%)$ & 10.58 years & NR \\
\hline Sadler-Gerhardt et al. [42] (USA) & 8 & Breast & $30-80$ & $\mathrm{~F}(100 \%)$ & NR & 10 months -5 years \\
\hline Thambyrajah et al. [43] (UK) & 20 & Head and neck & 67 & $\mathrm{M}(50 \%), \mathrm{F}(50 \%)$ & NR & $6-14$ months \\
\hline $\begin{array}{l}\text { Bishop et al. [44] (North } \\
\text { America) }\end{array}$ & 30 & Haematological & 51.3 & $\mathrm{M}(46.7 \%), \mathrm{F}(53.3 \%)$ & NR & 12.9 years \\
\hline Morris et al. [45] (Australia) & 209 & Mixed & 62.99 & NR & 2.9 years & NR \\
\hline Hoggan [46] (USA) & 18 & Breast & $37-65$ & $\mathrm{~F}(100 \%)$ & NR & $3-7$ years \\
\hline Lelorain et al. [47] (France) & 28 & Breast & NR & $\mathrm{F}(100 \%)$ & $5-15$ years & NR \\
\hline Tsuchiya et al. [30] (Japan) & 10 & Breast & 53.3 & $\mathrm{~F}(100 \%)$ & NR & 5.2 years \\
\hline Documet et al. [48] (USA) & 112 & Breast & $34-81$ & $\mathrm{~F}(100 \%)$ & $1.53-29.36$ years & NR \\
\hline Frye [49] (USA) & 6 & Mixed & $60-86$ & $\mathrm{M}(16.7 \%), \mathrm{F}(83.3 \%)$ & 14-32 years & NR \\
\hline Triplett [50] (USA) & 87 & Breast & $18-45$ & $\mathrm{~F}(100 \%)$ & 12 months & NR \\
\hline Connerty et al. [51] (Australia) & 15 & Mixed & $36-85$ & $\mathrm{M}(53.3 \%), \mathrm{F}(46.7 \%)$ & 15 years & NR \\
\hline Fauske et al. [52] (Norway) & 8 & Bone & $18-50$ & $\mathrm{M}(50 \%), \mathrm{F}(50 \%)$ & $3-10$ years & NR \\
\hline Mehrabi et al. [53] (Iran) & 18 & Breast & $31-65$ & $\mathrm{~F}(100 \%)$ & NR & $3-6$ months \\
\hline Cheng et al. [54] (China) & $29^{c}$ & Breast & 53.9 & $\mathrm{~F}(100 \%)$ & $6-180$ months & NR \\
\hline Martino et al. [55] (Italy) & 12 & Mixed & $25-70$ & $\mathrm{M}(25 \%), \mathrm{F}(75 \%)$ & NR & 3 years \\
\hline Matheson et al. [31] (UK) & 18 & Testicular & 34 & M (100\%) & NR & 6 months \\
\hline Hoogland [32] (USA) & 56 & Mixed & 72.45 & $\mathrm{M}(39.3 \%), \mathrm{F}(60.7 \%)$ & 36.71 months & NR \\
\hline Barthakur et al. [33] (India) & 15 & Breast & 57 & $\mathrm{~F}(100 \%)$ & 9.3 years & $>6$ months \\
\hline Raque-Bogdan et al. [34] (USA) & 13 & Breast & 34 & $\mathrm{~F}(100 \%)$ & 3.5 years & NR \\
\hline Adorno et al. [35] (USA) & 5149 & Mixed & NR & $\mathrm{M}(36 \%), \mathrm{F}(64 \%)$ & $2-10$ years & NR \\
\hline Inan et al. [36] (Turkey) & 13 & Breast & 48.7 & $\mathrm{~F}(100 \%)$ & NR & $7-22$ months \\
\hline Fallah et al. [37] (Iran) & 23 & Breast & 46.22 & $\mathrm{~F}(100 \%)$ & 26.96 months & NR \\
\hline
\end{tabular}

${ }^{\mathrm{a}} \mathrm{Age}$ is reported as the mean. Where the mean is not available, the range is given

${ }^{\mathrm{b}}$ Time since diagnosis and treatment is reported as the mean. Where the mean is not available, the range is given, or time is denoted from the inclusion criteria

${ }^{c}$ A sub-sample of 29 participants were involved in the qualitative stage (full sample $n=100$ )

${ }^{\mathrm{d}} N R$, not reported

Some reported a new willingness to express feelings and to understand complex emotions of others: 'Since developing the cancer, I can understand others' emotions like pain. I work with disabled people now, I cheer them up in my heart, saying things like walk forward step by step in your life' [40, p111]. Development of empathy helped survivors connect with others in similar situations and to appreciate that everyone has their own challenges: 'I have become less judgemental, I think in a way that each person has their own story. You never know what people have experienced or gone through. If something happens to someone, I put myself in his or her situation. I think about how others experience things' [45, p6086].

\section{New possibilities}

Findings from 23 studies mapped on to the 'New possibilities' outcome. Some survivors reported they had taken a new life path, re-evaluating their career and choosing to pursue other possibilities: 'I had a complete lifestyle change now. I mean, I became (employment position) for my business and chucked it in and spent the last year doing support work' [30, p286]. Similarly, participants describe re-prioritising what is important in life, often deciding to spend (more) time with family and friends: 'Decided that it was more important to schedule my life to spend time with friends than to spend time at work' [53, p1417]. 


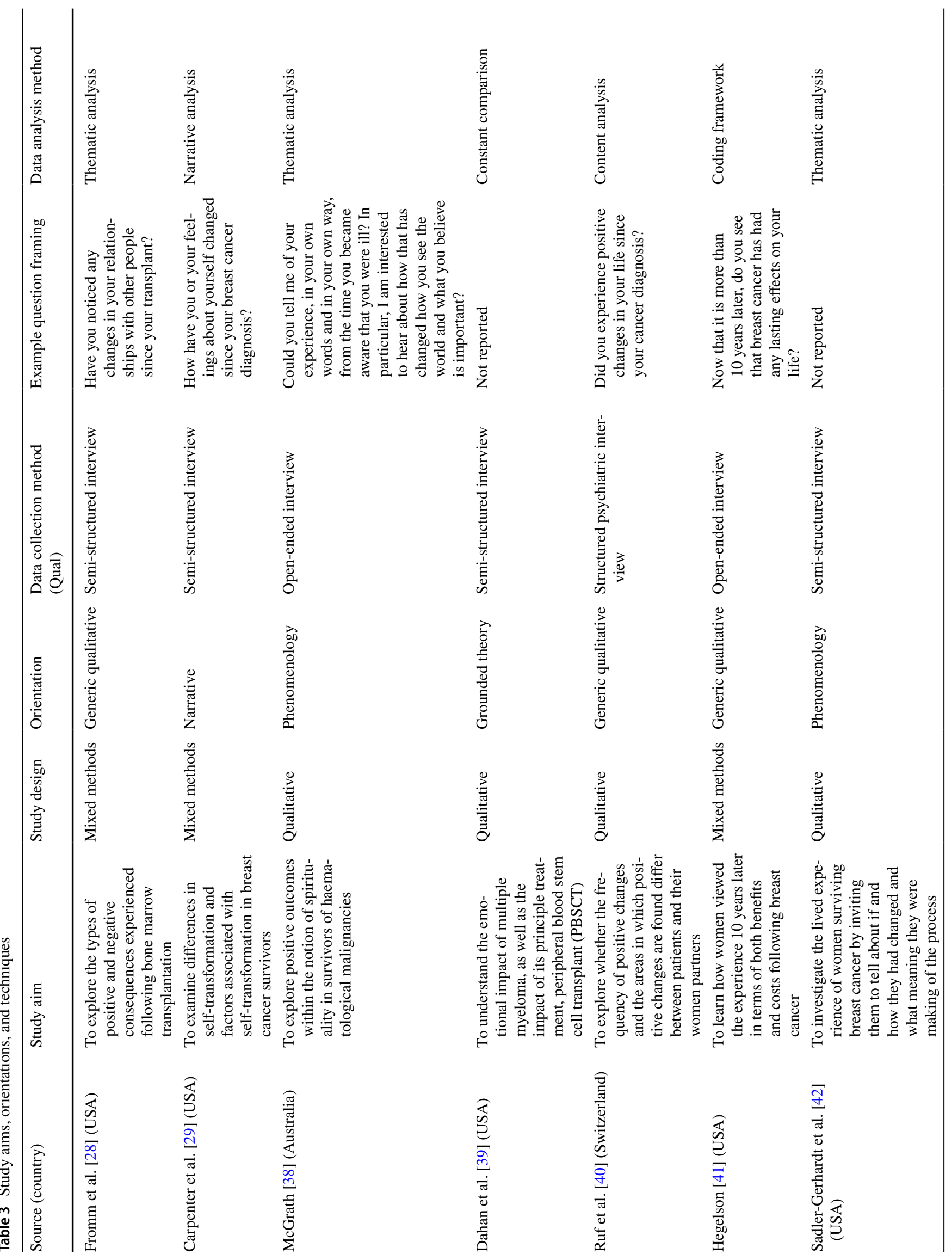




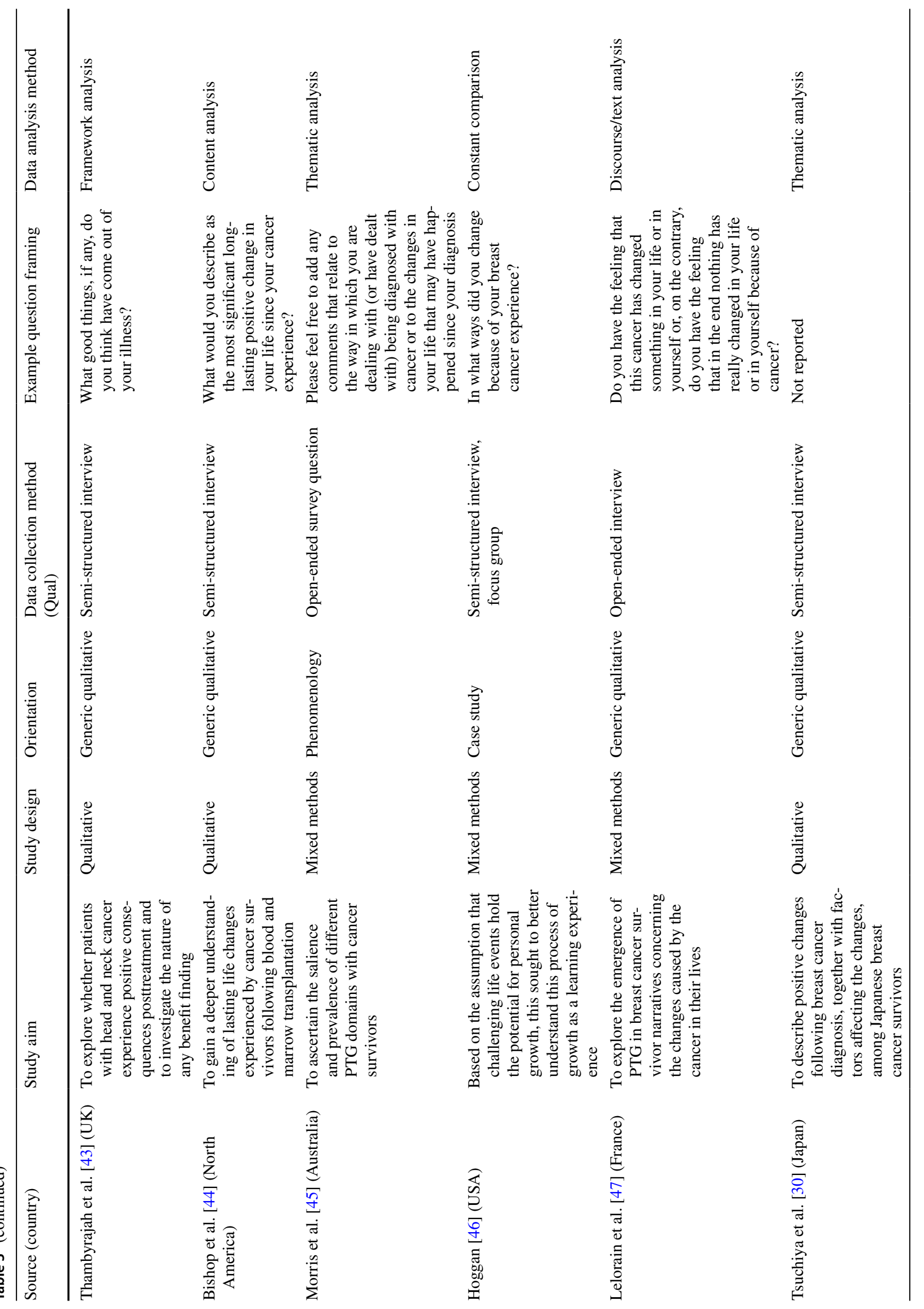




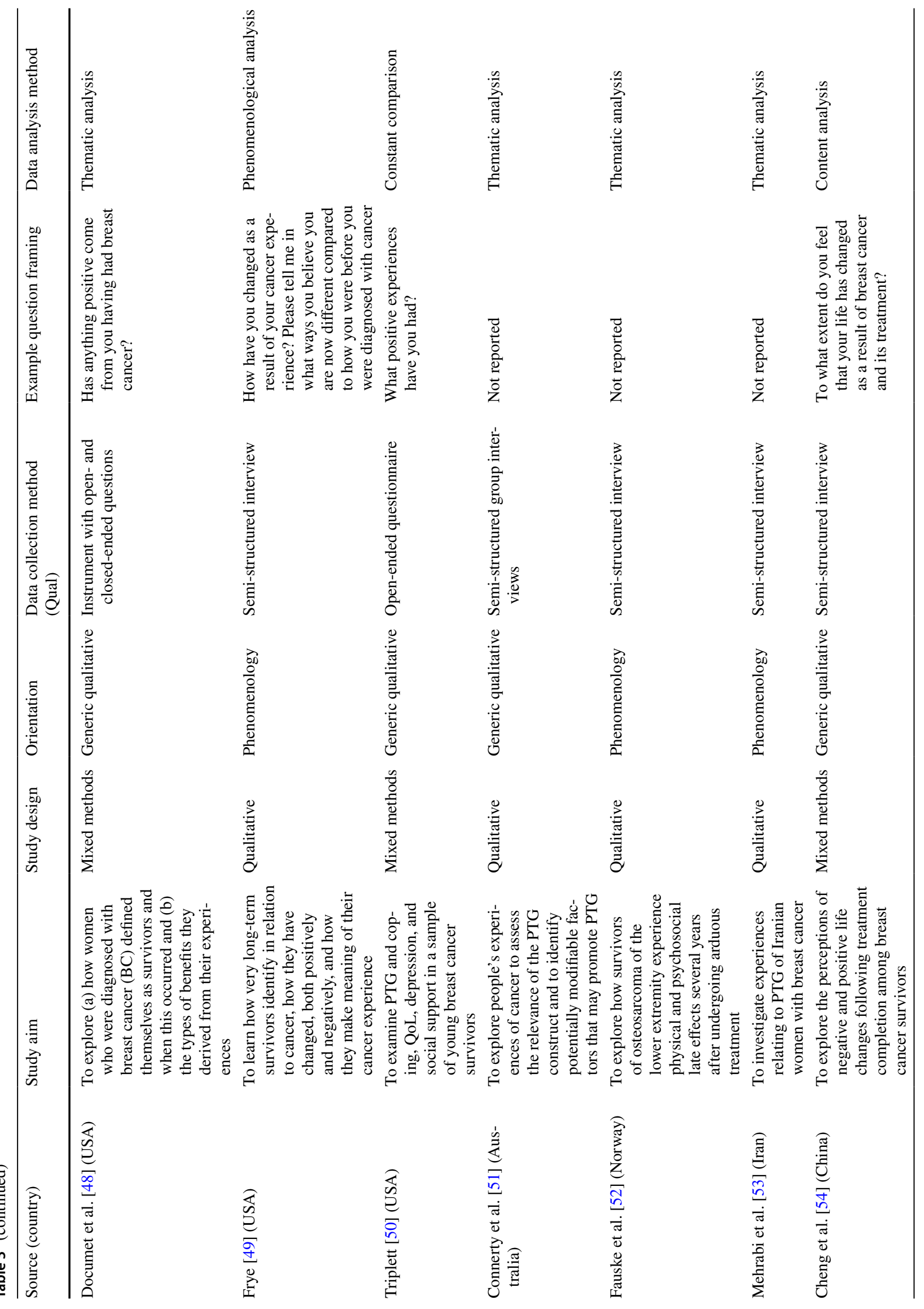




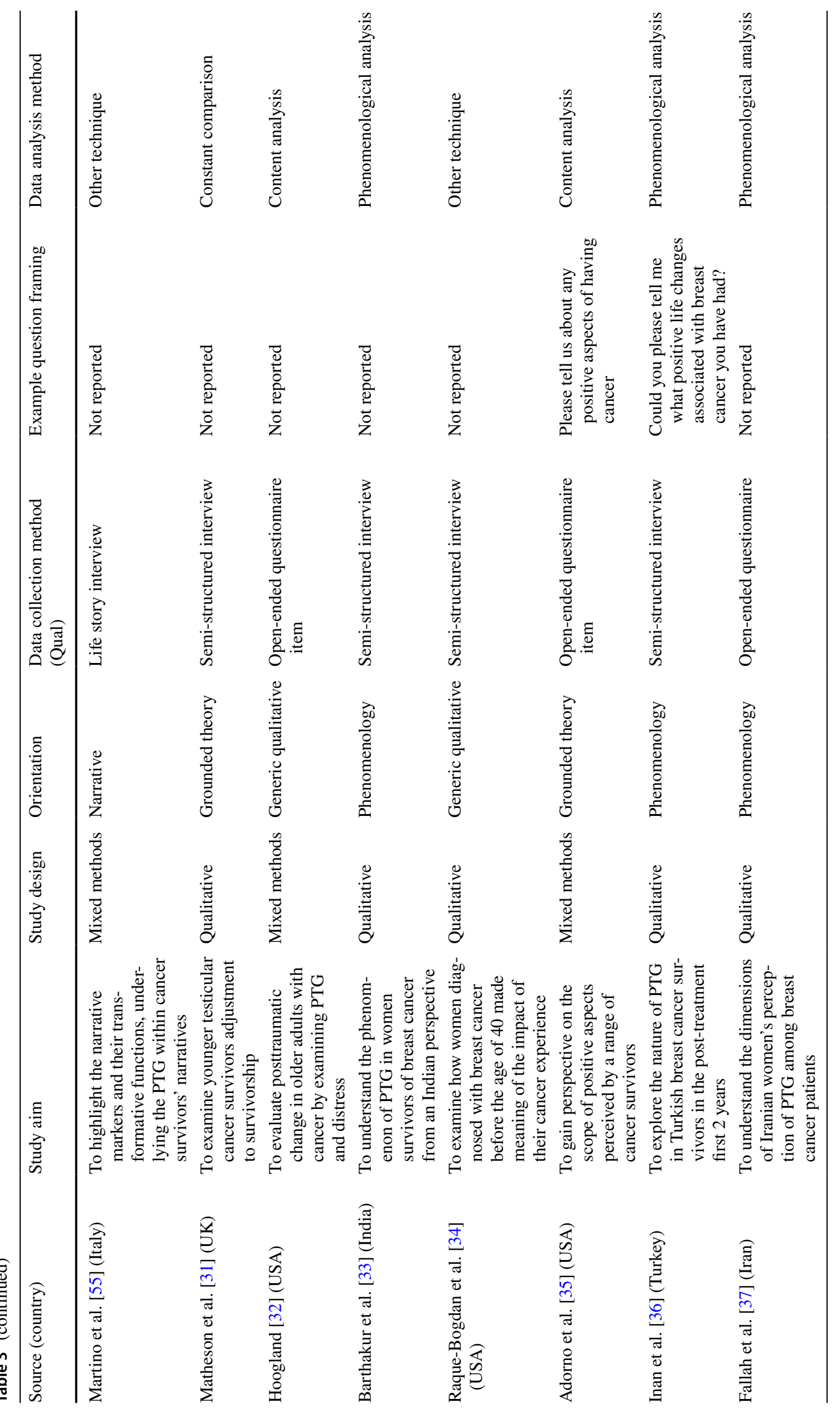


Health behaviour change was commonly reported as a positive change after cancer. Survivors described how they had learned to put themselves first and now chose to do things in their own best interests: 'I take better care of myself, [I am] more likely to say no to things' [41, p6]. Participants described lifestyle changes, ceasing unhealthy habits and adopting healthy eating and/or being more physically active. 'I thought if I continued the same lifestyle as before I got breast cancer, I would develop cancer again...I had been careless about foods...I have cut down the salt and limited my calorie intake and started avoiding some bad foods...' [40, p112]. A healthy lifestyle was sometimes perceived as a way to spend more time with family and friends: 'I have started an exercise program and am very healthy and want to stay in shape to do things with my daughter' [43, p64].

\section{Personal strength}

Twenty-seven studies reported findings within the 'Personal strength' outcome. Survivors reported strong feelings of self-efficacy following their cancer experience, and a belief that, if they can overcome cancer, then they can manage future challenges: 'Going through the experience with leukaemia, I grew even more confident, and we were talking about this and we think it is because I'd done the worst that life could dish out... I can do anything now' [30, p283]. Participants more resilience in day-to-day life: 'I can handle more. Can handle things better than others might do. Learned to speak up a little more and have become a little tougher' [45, p6086].

Some survivors described how their cancer journey had prompted a more positive attitude: 'Breast cancer made me a more positive person; a better person' [44, p339]. Selfacceptance grew, through identification as a cancer survivor and acknowledgement that what they had overcome was no small matter. This helped them adapt and/or rediscover, or find new, life pleasures: 'Being happy with myself, I accept what I am. I've changed my appearance. I discovered fashion, sexy underwear; sex again, my marriage, my husband, and everything. It was like being born again. I'm a success. I accept myself now... it's freed me from that feeling guilty about things' [35, p672].

\section{Appreciation of life}

Findings relevant to the 'Appreciation of life' outcome were reported in 25 studies. Survivors described how cancer had given them a greater appreciation of good health and a second chance at life: 'I understand the value of life along with my spouse and children. Also I perceived health is valuable and we should appreciate it' [45, p1243]. Enhanced appreciation of the beauty in life and being (more) grateful for small things were frequently reported: 'A heightened sense of appreciation of people and things of beauty' [52, p1416].

For some, cancer survivorship brought into perspective the importance of living in the moment. They described appreciating the positives in life because they had already been through worse: 'Problems don't worry me as much. I look at the beauty of life more than I used to before' [34, p674].

\section{Spiritual change}

Findings from 19 studies mapped to the 'Spiritual change' outcome. The predominant finding was that survivors' spiritual beliefs strengthened and/or faith deepened. Some survivors' beliefs led them to see having had cancer as something positive: 'My religious or spiritual beliefs... I feel much more confident they have been cemented a little bit more... I feel really strongly that I was really blessed' [36, p931]. Finding a deeper faith also helped cancer recovery: 'One thing that I did find as a positive after which was that my Christian faith deepened very significantly and I believe that was a very major factor in my recovery' [44, p339]. Survivors also credited their faith for their ability to manage challenges in day-to-day life: 'I have learned that my faith in God does make all things doable... good or bad' [43, p64]. Experiencing cancer also introduced some people to religion: 'It has led me to God. I learned a lot about myself, my life, and letting go of all those problems I was dealing with and looking at them in a different way' [41, p6].

\section{Discussion}

By determining the nature and scope of the current qualitative evidence base on PTG in cancer, our intention was to identify any gaps in the current literature. As with research in other areas of cancer survivorship, studies on experiences following breast cancer or of mixed groups of cancer survivors dominate the literature. This means evidence is lacking on how PTG might differ across different cancer populations. Breast cancer, for example, is associated with higher socio-economic status and 5-year survival is high [56]. It has been suggested that PTG is influenced by the individual's role pre-cancer and how their personal circumstances affect resilience and reaction to threat [14]. Socioeconomic circumstances may, therefore, influence perception of trauma or ability to successfully mediate distress and hence impact potential for PTG. Cancer treatment experiences also vary by site (and stage); some treatments may alter appearance and lead to distress and social difficulties [57] while others can be invisible but still have long-term negative consequences (e.g., colostomy) [58]. Feelings of 
stigma and shame associated with some cancers (e.g., lung) may influence emotional and psychological reactions to the diagnosis $[59,60]$. These issues, and the likely prognosis of the cancer, may all impact potential for, and experiences of, PTG. Research is warranted in more diverse patient populations - to explore all of this further.

Due to the dominance of breast cancer studies, the current literature mostly captures women's experiences of PTG. Quantitative studies in cancer, and studies of other traumatic events, have suggested that women have higher levels of PTG than men $[13,61]$. The reasons for this are not understood and might include differences between men and women in coping, appraisal of stressors, or cultural expectations; qualitative research in male cancers (e.g., prostate) or studies which seek to compare PTG experiences in men and women with the same cancer could shed light on these issues.

Cultural factors may influence PTG [62]. However, the studies identified here were mainly from highly developed Western countries (e.g., USA and Australia). Social networks, support, and integration will vary between countries [63]. The lack of cultural breadth in the current literature therefore limits potential to understand the influence of culture or other environmental factors on PTG.

Our scrutiny of study aims alongside methodological orientation indicates that the qualitative literature has largely focused on exploring and interpreting the lived experience of positive change following cancer. There was considerable variation in data collection methods, from unstructured interviews to open-ended questions placed at the end of surveys. Methodological details were commonly lacking. For example, many did not provide sample questions posed to interviewees, which could have provided insight into why findings were more focused on particular areas of PTG. Time since cancer diagnosis was inconsistently reported, despite being important for clarifying how and when PTG develops (e.g., how long do survivors struggle, reflect, or ruminate before PTG starts to develop?). Moreover, as all studies were cross-sectional (and most studies represented the combined experiences of survivors at different times from diagnosis), little is known about what initiates and sustains PTG, or how PTG manifests evolves over time or across the survivorship trajectory.

Our analysis of study findings demonstrates that PTG after cancer is seen across all five existing PTG outcomes, although not all outcomes emerged in every study. Many studies reported positive changes related to health behaviours. This is notable, given growing data on the role of lifestyle in cancer survival [64], and suggests that many may be receptive to advice and support around lifestyle change. However, such advice and support may need to be offered after someone has had time to reflect, rather than soon after diagnosis or end of treatment. Taking better care of one's own health and physical wellbeing appeared to be intertwined with other positive changes, most notably greater appreciation of life. The role of rumination and reflection in facilitating health behaviour change post-cancer, and links between behaviour change and other positive changes, are worthy of further exploration both in and of themselves, and in relation to the design and implementation of behaviour change interventions.

Although we found that all positive changes reported in studies could map to the existing PTG outcomes, it is important not to infer that the model therefore captures the full extent of psychological changes that may occur. The experience of PTG following cancer is distinct from other traumatic experiences where the trauma is acute (e.g., accident or naturally disaster) and although the growth outcomes may be broadly similar, the processes and influences may differ. Moreover, as we note earlier, the current evidence base includes a narrow group of cancers and countries and cultures; widening the evidence base could uncover changes and experiences that fall out with the current framework.

\section{Limitations}

To maintain a focus on PTG, we excluded studies that aimed to explore broader aspects of cancer survivorship experiences, and which might have reported, within other findings, one or more positive changes following cancer. These studies could, potentially, help fill some of the evidence gaps identified. We did not have resources for translation, and this may have contributed to the dominance of studies from Western countries.

\section{Conclusions}

Qualitative research provides strong confirmation that PTG is experienced by cancer survivors and illuminates the lived experience of positive psychological change. However, there are important gaps in evidence. Future studies should prioritise populations that are currently underrepresented (e.g., cancers with poorer prognosis; cancers which occur more in lower socio-economic groups, diverse cultural experiences) and seek to better understand gendered experiences of PTG in cancer survivorship. Longitudinal research would be particularly valuable to explore timing and trajectories of PTG post-cancer, and what influences this.

Supplementary Information The online version contains supplementary material available at https://doi.org/10.1007/s00520-021-06253-2. 
Author contribution Fiona Menger and Linda Sharp supported Nurul Asyiqin Mohammed Halim to conceive and design the study. Material preparation, data collection, and analysis were performed by Nurul Asyiqin Mohammed Halim, Fiona Menger, and Ben Rimmer, with support from Linda Sharp. The first draft of the manuscript was written by Fiona Menger (method, results, discussion), Ben Rimmer (results, data tabulation and checking, online resources), and Linda Sharp (introduction and revisions on all sections). All authors critically reviewed the manuscript and approved the final version.

Funding This review was supported by funding from The Newcastle upon Tyne Hospitals NHS Charity (BH172327) and a Newcastle University Student Research Scholarship.

Data availability Not applicable.

Code availability Not applicable.

\section{Declarations}

Ethics approval No ethical approval was required for a scoping review.

Consent to participate Not applicable.

Consent for publication Not applicable.

Conflict of interest The research leading to these results received funding from Newcastle upon Tyne Hospitals Charity (Award no. BH172327 made to final author Linda Sharp) and a Newcastle University Vacation Research Scholarship (awarded to Nurul Asyiqin Mohammed Halim).

Open Access This article is licensed under a Creative Commons Attribution 4.0 International License, which permits use, sharing, adaptation, distribution and reproduction in any medium or format, as long as you give appropriate credit to the original author(s) and the source, provide a link to the Creative Commons licence, and indicate if changes were made. The images or other third party material in this article are included in the article's Creative Commons licence, unless indicated otherwise in a credit line to the material. If material is not included in the article's Creative Commons licence and your intended use is not permitted by statutory regulation or exceeds the permitted use, you will need to obtain permission directly from the copyright holder. To view a copy of this licence, visit http://creativecommons.org/licenses/by/4.0/.

\section{References}

1. Miller KD, Nogueira L, Mariotto AB et al (2019) Cancer treatment and survivorship statistics, 2019. CA Cancer J Clin 69:363-385

2. Maddams J, Utley M, Møller H (2012) Projections of cancer prevalence in the United Kingdom, 2010-2040. Br J Cancer 107:1195-1202

3. Rowland JH, Kent EE, Forsythe LP et al (2013) Cancer survivorship research in Europe and the United States: where have we been, where are we going, and what can we learn from each other? Cancer 119:2094-2108. https://doi.org/10.1002/cncr.28060

4. Trevino KM, Naik AD, Moye J (2016) Perceived and actual change in religion/spirituality in cancer survivors: longitudinal relationships with distress and perceived growth. Psycholog Relig Spiritual 8:195

5. Moye J, Jahn A, Norris-Bell R et al (2020) Making meaning of cancer: a qualitative analysis of oral-digestive cancer survivors' reflections. J Health Psychol 25:1222-1235

6. Steinberg DM, Santiago RA, Tanenbaum ML et al (2020) "It made me the person I am today...": survivors of childhood, adolescent, and young adult cancer reflect on their experiences. J Adolesc Young Adult Oncol 9:239-246

7. Tedeschi GR, Calhoun GL (2004) Posttraumatic growth: conceptual foundations and empirical evdience. Psychol Inq 15:1-18

8. Sumalla EC, Ochoa C, Blanco I (2009) Posttraumatic growth in cancer: reality or illusion? Clin Psychol Rev 29:24-33. https:// doi.org/10.1016/j.cpr.2008.09.006

9. Shand LK, Cowlishaw S, Brooker JE et al (2015) Correlates of post-traumatic stress symptoms and growth in cancer patients: a systematic review and meta-analysis. Psychooncology 24:624634. https://doi.org/10.1002/pon.3719

10. Casellas-Grau A, Ochoa C, Ruini C (2017) Psychological and clinical correlates of posttraumatic growth in cancer: a systematic and critical review. Psychooncology 26:2007-2018. https:// doi.org/10.1002/pon.4426

11. Turner JK, Hutchinson A, Wilson C (2018) Correlates of posttraumatic growth following childhood and adolescent cancer: a systematic review and meta-analysis. Psychooncology 27:1100-1109

12. Jansen L, Hoffmeister M, Chang-Claude J et al (2011) Benefit finding and post-traumatic growth in long-term colorectal cancer survivors: prevalence, determinants, and associations with quality of life. Br J Cancer 105:1158-1165. https://doi.org/10. 1038/bjc.2011.335

13. Sharp L, Redfearn D, Timmons A et al (2018) Posttraumatic growth in head and neck cancer survivors: is it possible and what are the correlates? Psychooncology 27:1517-1523. https:// doi.org/10.1002/pon.4682

14. Seiler A, Jenewein J (2019) Resilience in cancer patients. Front. Psychiatry 10:1-35. https://doi.org/10.3389/fpsyt.2019.00208

15. Liu Z, Doege D, Thong MSY, Arndt V (2020) The relationship between posttraumatic growth and health-related quality of life in adult cancer survivors: a systematic review. J Affect Disord 276:159-168. https://doi.org/10.1016/j.jad.2020.07.044

16. Menger F, Patterson J, O'Hara J, Sharp L (2020) Research priorities on post-traumatic growth: where next for the benefit of cancer survivors? Psychooncology 29:1968-1970. https://doi. org/10.1002/pon.5490

17. Seers K (2015) Qualitative systematic reviews: their importance for our understanding of research relevant to pain. Br J pain 9:36-40

18. O'Cathain A, Croot L, Duncan EAS et al (2019) Guidance on how to develop complex interventions to improve health and health care. BMJ Open 9(8):e029954. https://doi.org/10.1136/ bmjopen-2019-029954

19. O'Cathain A, Croot L, Sworn K et al (2019) Taxonomy of approaches to developing interventions to improve health: a systematic methods overview. Pilot Feasibility Stud 5:41. https:// doi.org/10.1186/s40814-019-0425-6

20. Munn Z, Peters MDJ, Stern C et al (2018) Systematic review or scoping review? Guidance for authors when choosing between a systematic or scoping review approach. BMC Med Res Methodol 18:1-7. https://doi.org/10.1186/s12874-018-0611-x

21. Arksey H, O’Malley L (2005) Scoping studies: towards a methodological framework. Int J Soc Res Methodol Theory Pract 8:19-32. https://doi.org/10.1080/1364557032000119616

22. Booth A, Carroll C (2015) How to build up the actionable knowledge base: the role of "best fit" framework synthesis for 
studies of improvement in healthcare. BMJ Qual Saf 24:700708. https://doi.org/10.1136/bmjqs-2014-003642

23. Tricco AC, Lillie E, Zarin W et al (2018) PRISMA extension for scoping reviews (PRISMA-ScR): checklist and explanation. Ann Intern Med 169:467-473. https://doi.org/10.7326/ M18-0850

24. Tedeschi RG, Calhoun LG (1996) The posttraumatic growth inventory: measuring the positive legacy of trauma. J Trauma Stress 9:455-471. https://doi.org/10.1002/jts.2490090305

25. Tedeschi RG, Shakespeare-Finch J, Taku K, Calhoun LG (2018) Posttraumatic growth. Theory, research, and applications. Routledge, Abingdon, Oxon

26. Ouzzani M, Hammady H, Fedorowicz Z, Elmagarmid A (2016) Rayyan - a web and mobile app for systematic reviews. Syst Rev 5:. https://doi.org/10.1186/s13643-016-0384-4

27. Bradbury-Jones C, Breckenridge J, Clark MT et al (2017) The state of qualitative research in health and social science literature: a focused mapping review and synthesis. Int J Soc Res Methodol 20:627-645. https://doi.org/10.1080/13645579.2016. 1270583

28. Fromm K, Andrykowski MA, Hunt J (1996) Positive and negative psychosocial sequelae of bone marrow transplantation: implications for quality of life assessment. J Behav Med 19:221-240. https://doi.org/10.1007/BF01857767

29. Carpenter JS, Brockopp DY, Andrykowski MA (1999) Self-transformation as a factor in the self-esteem and well-being of breast cancer survivors. J Adv Nurs 29:1402-1411. https://doi.org/10. 1046/j.1365-2648.1999.01027.x

30. McGrath P (2004) Positive outcomes for survivors of haematological malignancies from a spiritual perspective. Int J Nurs Pract 10:280-291

31. Dahan JF, Auerbach CF (2006) A qualitative study of the trauma and posttraumatic growth of multiple myeloma patients treated with peripheral blood stem cell transplant. Palliat Support Care 4:365-387. https://doi.org/10.1017/s1478951506060470

32. Ruf M, Buchi S, Moergeli H, et al (2009) Positive personal changes in the aftermath of head and neck cancer diagnosis: a qualitative study in patients and their spouses. Head Neck April:513-520

33. Hegelson VS (2010) Corroboration of growth following breast cancer: ten years later. J Soc Clin Psychol 29(546-574):1. https:// doi.org/10.1016/j.bbi.2017.04.008

34. Sadler-Gerhardt CJ, Reynolds CA, Britton PJ, Kruse SD (2010) Women breast cancer survivors: stories of change and meaning. J Ment Heal Couns 32:265-282. https://doi.org/10.17744/mehc. 32.3.q14777j84kx3285x

35. Thambyrajah C, Herold J, Altman K, Llewellyn C (2010) "Cancer doesn't mean curtains": benefit finding in patients with head and neck cancer in remission. J Psychosoc Oncol 28:666-682. https:// doi.org/10.1080/07347332.2010.516812

36. Bishop MM, Curbow BA, Springer SH et al (2010) Comparison of lasting life changes after cancer and BMT: perspectives of longterm survivors and spouses. Psychooncology 20:926-934. https:// doi.org/10.1002/pon.1812

37. Morris BA, Shakespeare-Finch J, Scott JL (2012) Posttraumatic growth after cancer: the importance of health-related benefits and newfound compassion for others. Support Care Cancer 20:749-756

38. Hoggan CD (2011) Posttraumatic growth in breast cancer survivors as seen through the lens of adult learning theory.Doctoral Thesis. Columbia University

39. Lelorain S, Tessier P, Florin A, Bonnaud-Antignac A (2012) Posttraumatic growth in long term breast cancer survivors: relation to coping, social support and cognitive processing. J Health Psychol 17:627-639. https://doi.org/10.1177/1359105311427475

40. Tsuchiya M, Horn S, Ingham R (2013) Positive changes in Japanese breast cancer survivors: a qualitative study. Psychol Heal Med 18:107-116

41. Documet PI, Trauth JM, Key M et al (2012) Breast cancer survivors' perception of survivorship. Oncol Nurs Forum 39:309-315. https://doi.org/10.1188/12.onf.309-315

42. Frye JM (2013) The lived experience of very long-term cancer survivors: meaning-making and meanings made. Doctoral Thesis. Fielding Graduate University

43. Triplett KN (2013) Looking at the silver lining: posttraumatic growth in young breast cancer survivors. Doctoral Thesis. University of North Carolina

44. Connerty TJ, Knott V (2013) Promoting positive change in the face of adversity: experiences of cancer and post-traumatic growth. Eur J Cancer Care (Engl) 22:334-344

45. Fauske L, Bondevik H, Brul, et al (2015) Negative and positive consequences of cancer treatment experienced by long-term osteosarcoma survivors: a qualitative study. Anticancer Res 35:6081-6090

46. Mehrabi E, Hajian S, Simbar M et al (2015) Post-traumatic growth: a qualitative analysis of experiences regarding positive psychological changes among Iranian women with breast cancer. Electron Physician 7(5):1239-12346. https://doi.org/10.14661/ 1239

47. Cheng H, Sit JWH, Cheng KKF (2016) Negative and positive life changes following treatment completion: Chinese breast cancer survivors' perspectives. Support Care Cancer 24:791-798. https:// doi.org/10.1007/s00520-015-2845-Z

48. Martino ML, Freda MF (2016) Post-traumatic growth in cancer survivors: narrative markers and functions of the experience's transformation author note. Qual Rep 21:765-780

49. Matheson L, Boulton M, Lavender V et al (2016) Dismantling the present and future threats of testicular cancer: a grounded theory of positive and negative adjustment trajectories. J Cancer Surviv 10:194-205

50. Hoogland AI (2016) Posttraumatic growth among older adults with late-life cancer diagnoses. Doctoral Thesis. University of Kentucky

51. Barthakur MS, Sharma MP, Chaturvedi SK, Manjunath SK (2016) Posttraumatic growth in women survivors of breast cancer. Indian J Palliat Care 22:157-162

52. Raque-Bogdan TL, Hoffman MA, Joseph EC et al (2018) Everything is more critical: a qualitative study of the experiences of young breast cancer survivors. Couns Values 63:210-231. https:// doi.org/10.1002/cvj.12089

53. Adorno G, Lopez E, Burg MA et al (2018) Positive aspects of having had cancer: a mixed-methods analysis of responses from the American Cancer Society Study of Cancer Survivors-II (SCS-II). Psychooncology 27:1412-1425

54. Inan SF, Ustun B (2020) Post-traumatic growth in the early survival phase: from Turkish breast cancer survivors' perspective. Eur J Breast Heal 16:66-71. https://doi.org/10.5152/ejbh.2019. 5006

55. Fallah R, Keshmir F, Kashani FL et al (2012) Post-traumatic growth in breast cancer patients: a qualitative pheonomenological study. Middle East J Cancer 3:35-44

56. Cancer Research UK (2020) Breast cancer statistics. https://www. cancerresearchuk.org/health-professional/cancer-statistics/stati stics-by-cancer-type/breast-cancer\#heading-Zero. Accessed 17 May 2021

57. Nozawa K, Tomita M, Takahashi E et al (2017) Distress from changes in physical appearance and support through information 
provision in male cancer patients. Jpn J Clin Oncol 47:720-727. https://doi.org/10.1093/jjco/hyx069

58. Krouse RS, Herrinton LJ, Grant M et al (2009) Health-related quality of life among long-term rectal cancer survivors with an ostomy: manifestations by sex. J Clin Oncol 27:1664-4670. https://doi.org/10.1200/JCO.2008.20.9502

59. Threader J, Mccormack L (2016) Cancer-related trauma, stigma and growth: the "lived" experience of head and neck cancer. Eur J Cancer Care (Engl) 25:157-169. https://doi.org/10.1111/ecc. 12320

60. Chapple A, Ziebland S, McPherson A (2004) Stigma, shame, and blame experienced by patients with lung cancer: qualitative study. BMJ 328:1470

61. Vishnevsky T, Cann A, Calhoun LG et al (2010) Gender differences in self-reported posttraumatic growth: a meta-analysis. Psychol Women Q 34:110-120. https://doi.org/10.1111/j.1471-6402. 2009.01546.x

62. Cormio C, Romito F, Giotta F, Mattioli V (2015) Post-traumatic growth in the Italian experience of long-term disease-free cancer survivors. Stress Heal 31:189-196. https://doi.org/10.1002/smi. 2545
63. Banks J, Berkman L, Smith JP, et al (2010) Do cross-country variations in social integration and social interactions explain differences in life expectancy in industrialized countries? Int Differ Mortal Old Ages Dimens Sources 217-256

64. World Cancer Research Fund (2018) The cancer jigsaw. https:// www.wcrf-uk.org/uk/our-research/our-continuous-update-project. Accessed 17 May 2021

Publisher's note Springer Nature remains neutral with regard to jurisdictional claims in published maps and institutional affiliations. 